\title{
Human Pasteurella multocida Infection with Likely Zoonotic Transmission from a Pet Dog, Spain
}

\author{
Fátima Abreu, Carlos Rodríguez-Lucas, \\ M. Rosario Rodicio, Ana I. Vela, José Francisco \\ Fernández-Garayzábal, Pilar S. Leiva, \\ Fernando Cuesta, Dolores Cid, Javier Fernández
}

\begin{abstract}
Author affiliations: Principado de Asturias Sanitary Research Institute, Oviedo, Spain (F. Abreu, C. Rodriguez-Lucas, M.R. Rodicio, P.S. Leiva, J. Fernández); Central University Hospital, Asturias, Spain (F. Abreu, C. Rodriguez-Lucas, P.S. Leiva, J. Fernández); University of Oviedo, Asturias (C. Rodriguez-Lucas, M.R. Rodicio); Complutense University, Madrid, Spain (A.I. Vela, J.F. Fernández-Garayzábal, D. Cid); Principado de Asturias Health Care System, Pola de Siero Primary Care Center, Pola de Siero, Spain (F. Cuesta)
\end{abstract}

DOI: https://doi.org/10.3201/eid2406.171998

We report a case of urinary tract infection caused by an unusual genotype (sequence type 211) of Pasteurella multocida associated with human infection. Molecular genetic analysis of $P$. multocida isolates obtained from the human patient and his pet strongly suggests a zoonotic transmission of this bacterium.

$\mathrm{T}$ he bacterium Pasteurella multocida is one of the most frequent commensal and opportunistic pathogens found in domestic and wild animals worldwide (1). P. multocida is commonly cultured from the oropharynx of cats and dogs, and most human infections are associated with animal exposure, mainly from cats and dogs, and usually involve soft-tissue sites after animal bites or scratches (1). Among the wide clinical spectrum of invasive and noninvasive infections caused by $P$. multocida, urinary tract infections (UTIs) are rarely diagnosed, with $<20$ cases reported in the literature, most related to underlying diseases or urologic abnormalities $(2,3)$. Here we present a case of UTI caused by an unusual genotype of $P$. multocida.

An 83-year-old man was referred to a primary healthcare center with urinary complaints and fever without his general condition being impaired. The patient had previously had prostatic adenoma and inguinal hernia diagnosed. Since 2013, he had suffered recurrent UTIs, which were treated empirically with oral ciprofloxacin, resulting in favorable clinical progression. In the last episode, urine analysis revealed the presence of proteins, nitrites, blood (10-25 cells $/ \times 400$ microscope field), and abundant leukocytes ( $>100$ cells $/ \times 400$ microscope field). We sent a urine sample to the clinical microbiology laboratory of Hospital Universitario Central de Asturias and cultured in BBD CHROMagar Orientation Medium (Becton Dickinson, Heidelberg, Germany). We recovered bacterial counts $\left(>10^{5} \mathrm{CFU} / \mathrm{mL}\right)$ of an oxidase-positive gram-negative coccobacillus producing small $(\approx 1 \mathrm{~mm})$ white colonies in pure culture. Matrixassisted laser desorption/ionization time-of-flight mass spectrometry (Microflex; Bruker Daltonik GmbH, Bremen, Germany) identified the bacterium as P. multocida (score $>2$ ), and this finding was confirmed by 2 -strand sequencing of the 16S ribosomal RNA gene (4). We performed antimicrobial drug susceptibility testing by using the NegCombo Type 44 MicroScan panel (Beckman Coulter, Brea, CA, USA) and interpreted the results according to Clinical and Laboratory Standards Institute guidelines (5). The isolate was susceptible to all antimicrobial drugs tested ( $\beta$-lactams, $\beta$-lactams plus $\beta$-lactamase inhibitors, quinolones, colistin, tetracycline, tigecycline, chloramphenicol, trimethoprim/ sulfamethoxazole, fosfomycin, and nitrofurantoin) except aminoglycosides. We administered oral ciprofloxacin (500 mg every $12 \mathrm{~h}$ for $1 \mathrm{wk}$ ) to the patient, who had an excellent outcome, including bacteriuria eradication.

Further questioning of the patient indicated that he had a dog at home. We placed gingival swabs obtained from the animal in Amies transport medium and sent them to the hospital's clinical microbiology laboratory, where P. multocida was recovered. The animal isolate exhibited an antimicrobial drug susceptibility pattern identical to that of the patient isolate. Links between $P$. multocida human infections and pets are, in most cases, based on the information given by the patients indicating they have dogs or cats at home, but molecular studies aimed to associate $P$. multocida human infections with animal sources have rarely been conducted $(2,6)$. To determine the source of the UTI, we subjected the patient and dog isolates to molecular typing. We determined the capsular types and genetically characterized the isolates by using multilocus sequence typing (7) and pulsed-field gel electrophoresis with ApaI and SmaI restriction enzymes $(8,9)$. Both isolates belonged to capsular type $\mathrm{A}$ and to sequence type 211 , a genotype that has been previously isolated only from avian wound infections (https://pubmlst.org/pmultocida). Moreover, both isolates exhibited indistinguishable pulsotypes with the 2 enzymes used (Figure). These facts, together with the identical antimicrobial drug susceptibility pattern, demonstrate that they are the same strain, thus establishing a definitive epidemiologic link between the patient and his dog.

The patient denied any history of recent bites or scratches, but $P$. multocida infections without a bite history can occur in patients with certain co-occurring conditions (10). The patient in this case had several predisposing factors, including a prostatic adenoma, which might 

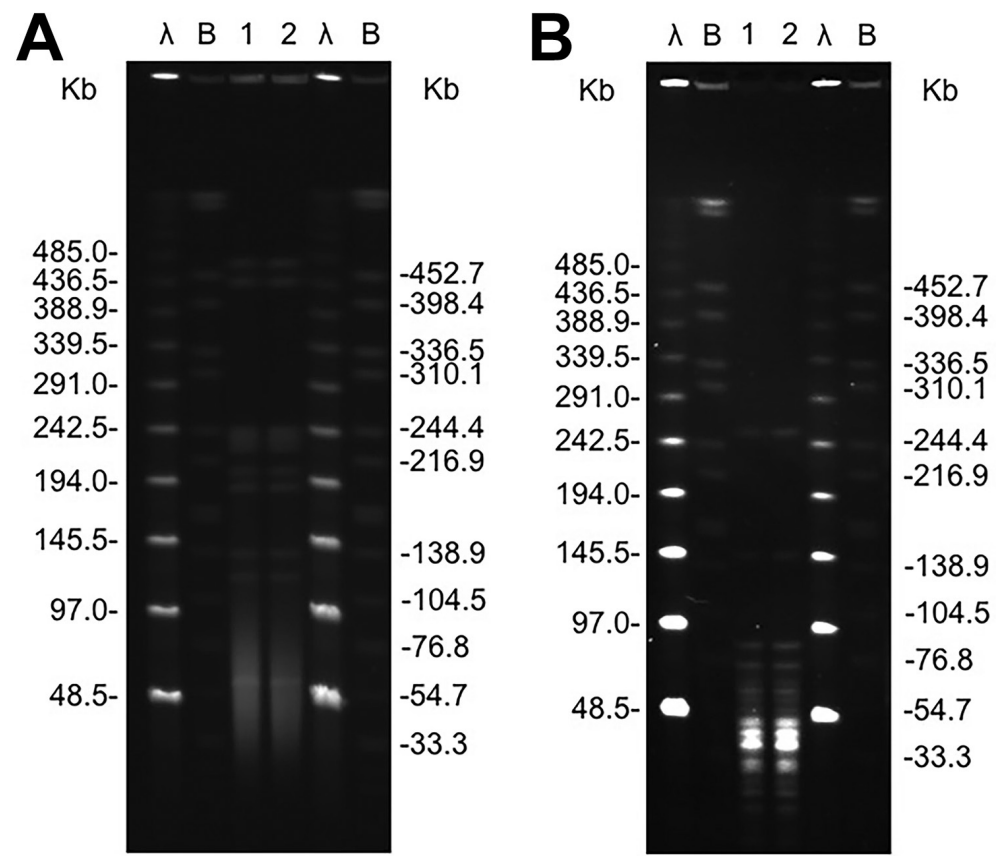

Figure. Pulsed-field gel electrophoresis profiles of Apal (A) and Smal (B) digested genomic DNA of Pasteurella multocida isolates from an 83-yearold man with a urinary tract infection (lane 1) and his pet dog (lane 2). Lanes $\lambda$ (Lambda Ladder PFGE marker [New England BioLabs, Ipswich, MA, USA]) and lanes B (DNA from Salmonella enterica serovar Branderup H9812 digested with $X b a l)$ used as molecular size standards.

have favored the infection by $P$. multocida because of mechanical alteration of the urinary tract. However, the specific route by which $P$. multocida reached the bladder could not be established. Although the possibility of a small scratch that had gone unnoticed cannot be ruled out, an alternative explanation could be a periurethral contamination of the patient after handling his dog, followed by colonization of the urethra and subsequent migration of the bacteria to the bladder. Although the specific route of transmission could not be elucidated in this case, pet owners and physicians should keep in mind that companion animals could be the source of infection by a wide range of opportunistic pathogens.

\section{About the Author}

Dr. Abreu is completing her medical residency in the Clinical Microbiology Department of the Hospital Universitario Central de Asturias in Spain. Her primary research interests are nosocomial infections and zoonoses.

\section{References}

1. Wilson BA, Ho M. Pasteurella multocida: from zoonosis to cellular microbiology. Clin Microbiol Rev. 2013;26:631-55. http://dx.doi.org/10.1128/CMR.00024-13

2. Liu W, Chemaly RF, Tuohy MJ, LaSalvia MM, Procop GW. Pasteurella multocida urinary tract infection with molecular evidence of zoonotic transmission. Clin Infect Dis. 2003;36: e58-60. http://dx.doi.org/10.1086/367649

3. Costanzo JT II, Wojciechowski AL, Bajwa RPS. Urinary tract infection with Pasteurella multocida in a patient with cat exposure and abnormal urinary tract physiology: case report and literature review. IDCases. 2017;9:109-11. http://dx.doi.org/10.1016/ j.idcr.2017.07.002
4. Xu J, Millar BC, Moore JE, Murphy K, Webb H, Fox AJ, et al. Employment of broad-range 16S rRNA PCR to detect aetiological agents of infection from clinical specimens in patients with acute meningitis - rapid separation of 16S rRNA PCR amplicons without the need for cloning. J Appl Microbiol. 2003;94:197-206. http://dx.doi.org/10.1046/j.1365-2672.2003.01839.x

5. Clinical and Laboratory Standards Institute. Methods for antimicrobial dilution and disk susceptibility testing of infrequently isolated or fastidious bacteria, 3rd edition (M45). Wayne (PA): The Institute; 2015.

6. Boyanton BL Jr, Freij BJ, Robinson-Dunn B, Makin J, Runge JK, Luna RA. Neonatal Pasteurella multocida subsp. septica meningitis traced to household cats: molecular linkage analysis using repetitive-sequence-based PCR. J Clin Microbiol. 2016;54:230-2. http://dx.doi.org/10.1128/JCM.01337-15

7. García-Alvarez A, Vela AI, San Martín E, Chaves F, Fernández-Garayzábal JF, Lucas D, et al. Characterization of Pasteurella multocida associated with ovine pneumonia using multi-locus sequence typing (MLST) and virulence-associated gene profile analysis and comparison with porcine isolates. Vet Microbiol. 2017;204:180-7. http://dx.doi.org/10.1016/ j.vetmic.2017.04.015

8. Lainson FA, Aitchison KD, Donachie W, Thomson JR. Typing of Pasteurella multocida isolated from pigs with and without porcine dermatitis and nephropathy syndrome. J Clin Microbiol. 2002;40:588-93. http://dx.doi.org/10.1128/JCM.40.2.588-593.2002

9. Kehrenberg C, Wallmann J, Schwarz S. Molecular analysis of florfenicol-resistant Pasteurella multocida isolates in Germany. J Antimicrob Chemother. 2008;62:951-5. http://dx.doi.org/10.1093/ $\mathrm{jac} / \mathrm{dkn} 359$

10. Giordano A, Dincman T, Clyburn BE, Steed LL, Rockey DC. Clinical features and outcomes of Pasteurella multocida infection. Medicine (Baltimore). 2015;94:e1285. http://dx.doi.org/10.1097/ MD.0000000000001285

Address for correspondence: Javier Fernández, Servicio de Microbiología, Hospital Universitario Central de Asturias, Av Roma s.n. 33011-Oviedo, Asturias, Spain; email: javifdom@gmail.com 